\title{
KANDUNGAN SAKARIN DALAM MINUMAN ES SIRUP DI SD KECAMATAN KOTA BARU JAMBI
}

\author{
Rina Fauziah ${ }^{1}$, Zunidra, Supriadi
}

\begin{abstract}
Snack food security need to considered because it plays an important role in the growth and development of children of school. The food often becomes the source of poisoning was snacks and desserts. The goal to analyze levels of artificial sweeteners saccharin as food additive in ice syrup.Type of research using survey method. Population is ice syrup sold in the canteen elementary school. Sample is 44 kind of ice syrup sold in canteen elementary school. Primary data was obtained through interviews with the seller of ice syrup and examination the Laboratory Academy health Analysis Jambi. Secondary data obtained from Department of Education and Culture of Jambi city related to number of elementary schools in district Kota Baru. The result show that out of 44 samples checked all contain saccharin and 13 samples exceeds standards. Number of traders selling drinks containing saccharinbecause the low level education, lack of information relating tofood additives and the absence security of the health service or BPOM Jambi.
\end{abstract}

Keywords : saccharin, ice syrup

\section{PENDAHULUAN}

Keamanan pangan jajanan sekolah perlu lebih diperhatikan karena berperan penting dalam pertumbuhan dan perkembangan anak sekolah. Makanan yang sering menjadi sumber keracunan adalah makanan ringan dan jajanan, karena biasanya makanan ini merupakan hasil produksi indutri makanan rumahan yang kurang dapat menjamin kualitas produk olahannya ( Sarwono, S. 2007 )

Makanan jajanan merupakan makanan dan minuman yang diolah oleh penjamah makanan di tempat penjualan dan atau disajikan sebagai makanan dan minuman siap santap untuk dijual bagi umum selain yang disajikan oleh jasa boga, rumah makan, restoran, dan hotel (Kepmenkes No 942/Menkes/VII/ 2003).

Pemanis buatan merupakan bahan tambahan pangan yang dapat

\begin{tabular}{lll}
\hline $1 \quad$ Dosen Jurusan & Kesehatan \\
Lingkungan $\quad$ Politeknik & Kesehatan \\
Kemenkes Jambi & &
\end{tabular}

menyebabkan rasa manis pada pangan, tetapi tidak memiliki nilai gizi. Bahan pemanis ini adalah hasil buatan manusia, oleh karena itu bahan tersebut tidak diproses secara alamiah. Pemanis buatan yang telah dikenal dan banyak digunakan adalah sakarin. Pedagang kecil dan industri rumahan seringkali menggunakan pemanis buatan karena dapat menghemat biaya produksi. (Cahyadi, W. 2008)

Berdasarkan pengambilan data di Dinas Pendidikan dan Kebudayaan Kota Jambi Tahun 2016 bahwa jumlah SD Negeri yang ada di Kecamatan Kota Baru berjumlah 40. Hasil wawancara penulis dengan guru UKS di SD Negeri 206/IV dan SD Negeri 212/IV Kecamatan Kota Baru Jambi bahwa anak-anak sekolah umumnya setiap hari menghabiskan $1 / 4 \quad$ waktunya disekolah. Sekitar 5\% anak-anak tersebut membawa bekal dari rumah dan berdasarkan observasi penulis dikantin SD Negeri 206/IV dan SD Negeri 212/IV Kecamatan Kota Baru 
Jambi bahwa minuman yang dijual dikantin sekolah adalah es sirup.

Hasil kajian terbatas yang dilakukan BPOM Provinsi Jambi Tahun 2013 di beberapa Sekolah Dasar (SD) yang ada di Kecamatan Kota Baru Jambi menemukan banyaknya anak sekolah yang mengkonsumsi makanan dan minuman yang mengandung kadar pemanis buatan sakarin dengan tingkat yang tidak aman. Anak-anak SD yang diteliti, ditemukan konsumsi sakarin sebesar 12,2 \% dari nilai ADI (acceptable daily intake).

Sakarin tidak dimetabolisme oleh tubuh, lambat diserap oleh usus dan cepat dikeluarkan melalui urin tanpa perubahan. Pada suatu penelitian diperoleh penggunaan sakarin dapat merangsang terjadinya tumor di kandung kemih. Menurut Peraturan Menteri Kesehatan RI No.033/Menkes/Per/IX/2012 tentang bahan tambahan pangan kadar maksimum sakarin yang diperbolehkan adalah $300 \mathrm{mg} / \mathrm{kg}$. Pengkonsumsian sakarin dalam dosis yang lebih akan mengakibatkan kanker kandung kemih. Selain itu akan menyebabkan tumor paru, hati dan limpa.

Berdasarkan latar belakang tersebut penulis tertarik melakukan penelitian tentang kandungan sakarin dalam minuman es sirup di SD Kecamatan Kota Baru Jambi.

\section{METODE PENELITIAN}

Jenis Penelitian ini menggunakan metode survey, sampel dilakukan secara kualitatif dan kuantitatif di laboratorium, selanjutnya pembahasan dilakukan secara deskriptif yaitu menggambarkan kandungan sakarin dalam minuman es sirup di SD Kecamatan Kota Baru Jambi. Tujuan Penelitian untuk mengetahui ada tidaknya kandungan sakarin dalam minuman es sirup di SD Kecamatan Kota Baru Jambi dan Untuk mengetahui kandungan sakarin yang terdapat dalam minuman es sirup di SD Kecamatan Kota Baru Jambi. Lokasi pengambilan sampel dilakukan di SD Kecamatan Kota Baru Jambi. Jumlah SD di Kecamatan Kota Baru sebanyak 40, pengambilan sampel minuman es sirup dilakukan di 37 SD Kecamatan Kota Baru yang menjual es sirup dan dari 37 SD di Kecamatan Kota Baru terdapat 44 jenis sampel minuman es sirup yang dijadikan sampel penelitian. Pemeriksaan sampel di laboratorium Akademi Analis Kesehatan Jambi. Populasi dalam penelitian ini adalah pangan jajanan berupa minuman es sirup yang dijual di kantin SD Kecamatan Kota Baru Jambi. Sampel dalam penelitian ini adalah 44 jenis minuman es sirup yang dijual di kantin SD Kecamatan Kota Baru Jambi. Jumlah SD di Kecamatan Kota Baru sebanyak 40,

Teknik Pengumpulan Data dilakukan dengan cara survey pendahuluan ke SD Kecamatan Kota Baru Jambi, kemudian mengisi kuesioner dan melakukan pengambilan sampel minuman es sirup serta melakukan pemeriksaan ada tidaknya sakarin dalam minuman es sirup serta melakukan pemeriksaan jumlah kandungan sakarin yang terdapat dalam minuman es sirup. Pemeriksaan sampel dilakukan di laboratorium Akademi Analis Kesehatan Jambi. Analisa Data yang diperoleh di lapangan dilakukan pemeriksaan labor di Akademi Analis Kesehatan Jambi dan sampel dianalisis secara kualitatif dan kuantitatif di laboratorium, selanjutnya pembahasan dilakukan secara deskriptif dalam bentuk tabel dan narasi. 


\section{HASIL DAN PEMBAHASAN}

Berdasarkan hasil penelitian yang dilaksanakan di Laboratorium Akademi Analis Kesehatan Jambi tentang kandungan sakarin dalam minuman es sirup di SD Kecamatan Kota Baru Jambi di peroleh hasil sebagai berikut :

\section{Tabel 1}

\section{Kandungan Sakarin Dalam} Minuman Es Sirup di SD Kecamatan Kota Baru Jambi

\begin{tabular}{cccc}
\hline No & Sampel & $\begin{array}{c}\text { Kandungan } \\
(\mathrm{mg} / \mathrm{kg})\end{array}$ & Keterangan \\
\hline 1. & Sampel 1 & 74,04 & \\
2. & Sampel 2 & 185 & \\
3. & Sampel 3 & 41,14 & \\
4. & Sampel 4 & 641,72 & Melebihi \\
& & & Standar \\
5. & Sampel 5 & 78,16 & \\
6. & Sampel 6 & 6,33 & \\
7. & Sampel 7 & $1,756,47$ & Melebihi \\
& & & Standar \\
8. & Sampel 8 & $1,308,10$ & Melebihi \\
& & & Standar \\
9. & Sampel 9 & 49,36 & \\
10. & Sampel 10 & 125 & \\
11. & Sampel 11 & 403 & \\
12. & Sampel 12 & 250 & \\
13. & Sampel 13 & 65 & \\
14. & Sampel 14 & 150 & \\
15. & Sampel 15 & 28 & \\
16. & Sampel 16 & 165 & \\
17. & Sampel 17 & 402,28 & Melebihi \\
18. & Sampel 18 & 173,53 & Standar \\
19. & Sampel 19 & 425,94 & Melebihi \\
20. & Sampel 20 & 228,74 & Standar \\
21. & Sampel 21 & 252,41 & \\
22. & Sampel 22 & 197,19 & \\
23. & Sampel 23 & 362,84 & Melebihi \\
24. & Sampel 24 & 212,97 & Standar \\
25. & Sampel 25 & 331,29 & Melebihi \\
26. & Sampel 26 & 268,18 & Standar \\
27. & Sampel 27 & 370,73 & Melebihi \\
& & & Standar
\end{tabular}

28. Sampel $28 \quad 205,08$

29. Sampel $29 \quad 323,40$

30. Sampel $30 \quad 260,30$

31. Sampel $31 \quad 165,64$

32. Sampel $32 \quad 418,05$

33. Sampel $33 \quad 386,50 \quad$ Melebihi

34. Sampel $34 \quad 441,72 \quad$ Melebihi

35. Sampel $35 \quad 425,94 \quad \begin{gathered}\text { Standar } \\ \text { Melebihi }\end{gathered}$

36. Sampel $36 \quad 31,55$

37. Sampel $37 \quad 55,21$

38. Sampel $38 \quad 39,43$

39. Sampel $39 \quad 47,32$

40. Sampel $40 \quad 70,94$

41. Sampel $41 \quad 31,55$

42. Sampel $42 \quad 23,66$

43. Sampel $43 \quad 47,32$

44. Sampel $44 \quad 15,77$

Melebihi
Standar

. Sampel 44 15,77

Dari Tabel 1 menunjukkan bahwa dari 44 jenis sampel minuman es sirup yang diperiksa semua sampel minuman es sirup mengandung sakarin dan terdapat 13 jenis minuman es sirup yang melebihi standar sesuai dengan Peraturan Menteri Kesehatan RI No.033/Menkes/Per/IX/2012 tentang bahan tambahan pangan bahwa kadar maksimum sakarin yang diperbolehkan adalah $300 \mathrm{mg} / \mathrm{kg}$. Menurut BPOM RI, 2003 Salah satu masalah keamanan pangan yang masih memerlukan pemecahan masalahnya yaitu penggunaan bahan tambahan pada bahan makanan untuk berbagai keperluan. Diantara beberapa Bahan Tambahan Makanan yang sangat sering digunakan salah satunya adalah pewarna makanan. Menurut Renawati, I (2010), penggunaan zat pewarna pada makanan dan minuman adalah untuk mempertajam atau menyeragamkan warna bahan makanan yang mengalami perubahan 
pada saat atau proses pengolahan, memberi warna pada makanan yang tidak berwarna agar keliatan lebih menarik. Penelitian zat pewarna pada minuman sirup dilakukan karena mengingat banyaknya zat pewarna yang digunakan sebagai bahan tambahan pangan baik yang diizinkan maupun yang tidak diizinkan. Menurut Permenkes RI No.942/Mennkes/VII/2003 tentang Bahan Tambahan Makanan bahwa tidak semua zat pewarna yang digunakan merupakan zat pewarna yang diizinkan.

Hasil penelitian yang dilakukan di laboratorium Akademi Analis Kesehatan Jambi dari 44 jenis sampel minuman es sirup yang diperiksa semua minuman es sirup mengandung sakarin dan terdapat 13 jenis minuman es sirup yang mengandung sakarin melebihi standar Peraturan Menteri Kesehatan RI No. 033/ Menkes/ Per/ IX/ 2012 tentang bahan tambahan pangan yaitu pada sampel 4 mengandung sakarin sebesar $641,72 \mathrm{mg} / \mathrm{kg}$, pada sampel 7 mengandung sakarin sebesar $1.756,47 \mathrm{mg} / \mathrm{kg}$, pada sampel 8 mengandung sakarin sebesar $1.308,10 \mathrm{mg} / \mathrm{kg}$, pada sampel 17 mengandung sakarin sebesar 402,28 pada sampel 19 mengandung sakarin sebesar 425,94 pada sampel 23 mengandung sakarin 362,84 pada sampel 25 mengandung sakarin sebesar 331,29 pada sampel 27 mengandung sakarin sebesar 370,73 pada sampel 29 mengandung sakarin sebesar 323,40 pada sampel 32 mengandung sakarin sebesar 418,05 pada sampel 33 mengandung sakarin sebesar 386,50 pada sampel 34 mengandung 441,72 dan pada sampel 35 mengandung sakarin 425,94. Es sirup yang mengandung sakarin ditandai dengan terbentuknya endapan putih pada ujung tabung reaksi.
Pemanis berfungsi untuk meningkatkan cita rasa dan aroma. Pemanis merupakan senyawa kimia yang sering ditambahkan dan digunakan untuk keperluan produk olahan pangan, industri, serta makanan dan minuman. Penggunaan sakarin yang semula hanya ditunjukkan pada produk khusus bagi penderita diabetes melitus saat ini penggunaan sakarin meluas pada berbagai produk makanan secara umum.

Sakarin yang mempunyai rasa
pahit yang disebabkan oleh
kemurnian yang rendah dari proses
sintesis. Sakarin secara luas
digunakan sebagai pengganti gula
karena mempunyai sifat non
karsinogenik, nilai kalori rendah, dan
harganya relative murah. Penambahan sakarin pada makanan dan minuman yang melebihi batas yang telah ditentukan tidak diketahui oleh penjual karena kurangnya informasi (Krisno, B. 2009).

Berdasarkan hasil wawancara penulis dengan pedagang minuman es sirup dan pengisian kuesioner bahwa rata-rata umur pedagang minuman es sirup 30-40 tahun. Semua pedagang minuman jajanan sudah beroperasi lebih dari dua tahun dan memiliki latar belakang pendidikan lulusan Sekolah Menengah Atas dan juga Sekolah Menengah Pertama, tetapi ada juga yang pendidikan terakhirnya dari Sekolah Dasar. Latar belakang pendidikan yang rendah berarti pengetahuan yang dimilikinya juga relatif kurang, termasuk pengetahuan tentang zat pemanis buatan sehingga menjadi salah satu faktor bagi penjual minuman jajanan untuk menggunakan bahan pemanis buatan melebihi nilai ambang batas. Kurangnya pengetahuan penjual tentang keamanan pangan, akan mendorong semakin meningkatnya 
produk minuman jajanan yang tidak aman untuk dikonsumsi, sehingga latar belakang pedagang berkaitan erat dengan keamanan produk minuman jajanan yang mereka jual dalam hal ini dilihat dari tingkat pendidikan.

Menurut Murtjipto, 2010 Es Sirup adalah cairan yang memiliki kadar gula terlarut yang tinggi yang dibungkus mengguna kan plastik. Es sirup tidak hanya langsung dibuat dengan gula namun beredar dalam kemasan dengan penambahan pemanis, pengawet, pewarna hingga es sirup berbagai macam rasa. Batas kadar sakarin berdasarkan Peraturan Menteri Kesehatan RI No.033/Menkes/Per IX/2012 tentang bahan tambahan pangan bahwa kadar maksimum sakarin yang diperbolehkan adalah $300 \mathrm{mg} / \mathrm{kg}$.

Es sirup yang dijual di Kantin Sekolah dapat dilihat dari warnanya yang mencolok dan rasanya yang sangat manis. Es sirup dijual secara bebas dijual di sekolahan, tempat wisata dan pasar.

Sakarin didalam tubuh tidak mengalami metabolisme sehingga dieksresikan melalui urine tanpa perubahan kimia. Sejalan dengan penelitian yang dilakukan oleh Adriani tentang penggunaan sakarin pada minuman jajanan yang dijajakan pada Sekolah Dasar di Gresik menunjukkan bahwa Dari hasil penelitian menunjukkan bahwa 10 sampel minuman yang diperiksa di BBLK Surabaya, 5 sampel positif mengandung sakarin. Hal ini berbeda dengan hasil temuan BPOM RI Tahun 2003 dari 12 jenis makanan dan minuman jajanan yang dijual di kompleks SD Sudirman kota Makassar ditemukan 15 jenis jajanan masih menggunakan pemanis sintetik berupa sakarin ( Adriani, M. 2012).

Ciri-ciri makanan dan minuman yang menggunakan pemanis buatan antara lain : Memiliki rasa manis yang pekat, Ada rasa pahit yang tertinggal, membuat tenggorokan menjadi kering, Minuman yang diberi pemanis buatan lebih encer dibandingkan dengan minuman yang mengandung gula asli. (Permenkes RI No.722/Menkes/Per /IX/1988 ).

\section{SIMPULAN}

Dari 44 jenis sampel minuman es sirup yang diperiksa di laboratorium Akademi Analis Kesehatan Jambi semua sampel mengandung sakarin dan terdapat 13 jenis minuman es sirup yang mengandung sakarin melebihi standar Peraturan Menteri Kesehatan RI No.033/Menkes/Per/IX/2012 yaitu $300 \mathrm{mg} / \mathrm{kg}$. Saran bagi Pedagang Hendaklah lebih banyak mencari informasi batas penggunaan pemanis buatan karena bila berlebihan akan membahayakan konsumen.

\section{DAFTAR PUSTAKA}

Adriani, M. 2012. Pengantar Gizi Masyarakat Jakarta : Kencana Prenada Media Group.

BPOM Provinsi Jambi, 2013. Data persentase kosumsi sakarin. Jambi Sehat.

BPOM RI. Jajanan Anak Sekolah. Jakarta ; 2003.

Cahyadi, W. 2008. Analisis Dan Aspek Kesehatan Bahan Tambahan Pangan, Jakarta : PT Bumi Aksara.

Dinas pendidikan dan Kebudayaan, 2016. Data Jumlah SD di Kecamatan Kota Baru Kota Jambi.

Kepmenkes Nomor 942/ Menkes/ VII/2003 Tentang Makanan Jajanan.

Krisno, B. Dasar-Dasar Ilmu Gizi, Malang : UMM Press, 2009. 
Moertjipto, 2010. Proses Pengolahan Pangan. Rieneka Cipta, Jakarta.

Permenkes No 033/Menkes/Per/IX/ 2012 Tentang Bahan

Tambahan Pangan.

Permenkes RI No.722/ Menkes/Per/ IX1988 Bahan Tambahan Makanan.

Renawati, I. 2010. Teori Analisis Buatan. Balai Industri Semarang.

Sarwono, S. 2007. Sosiologi Pangan dan HACCP. Edisi I, Graha Ilmu : Yogyakarta. 